\title{
Impact of Hellenic Arc Tsunamis on Corsica (France)
}

\author{
Audrey Gailler, ${ }^{1}$ (D) F. Schindelé, ${ }^{1}$ and H. Hébert ${ }^{1}$
}

\begin{abstract}
In the historical period, the Eastern Mediterranean has been devastated by several tsunamis, the two most damaging were those of $\mathrm{AD} 365$ and $\mathrm{AD} 1303$, generated by great earthquakes of magnitude $>8$ at the Hellenic plate boundary. Recently, events of 6-7 magnitude have occurred in this region. As the French tsunami warning center has to ensure the warning for the French coastlines, the question has raised the possibility for a major tsunami triggered along the Hellenic arc to impact the French coasts. The focus is on the Corsica coasts especially, to estimate what would be the expected wave heights, and from which threshold of magnitude it would be necessary to put the population under cover. This study shows that a magnitude 8.0 earthquake nucleated along the Hellenic arc could induce in some cases a tsunami that would be observed along the Corsica coasts, and for events of 8.5 magnitude amplitudes exceeding $50 \mathrm{~cm}$ can be expected, which would be dangerous in harbors and beach areas especially. The main contribution of these results is the establishment of specific thresholds of magnitude for the tsunami warning along the French coasts, 7.8 for the advisory level (coastal marine threat with harbors and beaches evacuation), and 8.3 for the watch level (inland inundation threat) for tsunamis generated along the Hellenic arc.
\end{abstract}

Key words: Tsunami, hazard assessment, warning system, amplification law, Mediterranean basin.

\section{Introduction}

On April 16, 2015, at 18h07 TU, a magnitude $M_{\mathrm{w}}=6.0$ earthquake occurred in the Eastern Mediterranean basin, along the SE coasts of Crete (Fig. 2). As expected for this level of magnitude, no tsunami was observed following this event. The French tsunami warning center (CENALT) detected and characterized the earthquake, and informed the national civil protection authorities that no tsunami impact was expected on the French coastlines. As, at

1 CEA, DAM, DIF, Arpajon Cedex 91297, France. E-mail: audrey.gailler@gmail.com the time of this event, no alert procedure was defined for tsunami generated in the Eastern Mediterranean (because no impact was expected), this information was provided by a phone call. However, a misunderstanding with message disseminated by other tsunami warning center, providing estimated tsunami arrival time along the French coastlines, led to an advisory procedure in the harbor of Bastia in Corsica (harbors and beaches people evacuation).

To avoid this kind of confusion in the future, we investigate in more detail the tsunamigenic potential of earthquakes occurring along the Hellenic subduction zone, in order to evaluate the minimum magnitude needed for a tsunami to cross from the Eastern to the Western Mediterranean basin, as well as their impact expected for the largest events. The tsunami risk due to an $M \geq 7.5$ earthquake triggered along the Hellenic arc is clearly assessed (e.g., Papadopoulos 2003; Papadopoulos et al. 2007). The main goal of this study is to identify which French coastlines that would be impacted by such events, especially along Corsica, and to draw consequences on earthquake monitoring in this area.

Nevertheless, concerning the seismotectonics of this region, lots of unknowns remain regarding the geometry and the rheology of the Hellenic subduction zone at depth, and also regarding the potential tsunamigenic seismic source parameters. Having recourse to worst-case scenarios is a leading deterministic conservative approach to define and evaluate the tsunami hazard in a given region.

Tinti et al. (2005) studied two worst-case scenarios (with a pure thrust mechanism) in the Eastern Mediterranean: the first one breaking the Western part of the Hellenic subduction zone parallel to the trench (inspired from the AD 365 event $-M$ 8.3) and the second one breaking the easternmost part of the arc in front of the SW Turkish coast (analog to the 


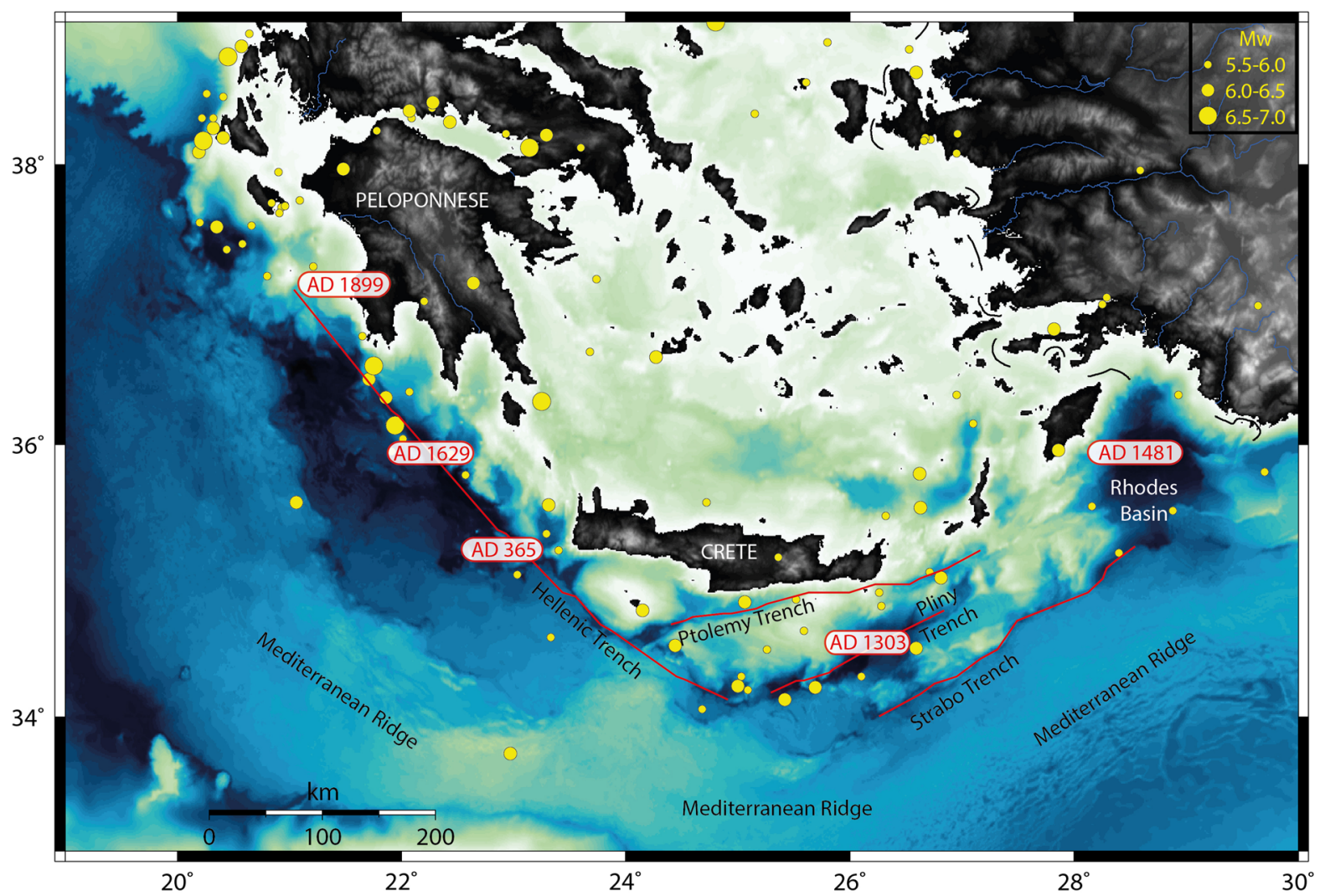

Figure 1

Seismotectonic setting of the Hellenic plate boundary zone. Yellow circles represent $M_{\mathrm{w}} \geq 5.5$ earthquakes from 1976 to 2016 (GCMT catalog from 1976 to September 2004 (Dziewonski et al. 1981; Ekström et al. 2012), and EMSC catalog October 2004 to now). Dates (AD 365-AD 1899) refer to approximate source areas of tsunamigenic earthquakes (see England et al. 2015) modeled in this study

AD 1303 event $-M$ 8.0). Following their modeling, none generates significant effects in Western Mediterranean. However, the rupture zone parameters chosen bring in long and narrow faults (more than $400 \mathrm{~km}$ length for the $M 8.3,35$ to $38 \mathrm{~km}$ width), with a low dip $\left(20^{\circ}\right)$ and a 5 to $10 \mathrm{~m}$ slip (for the $M 8.0$ and 8.3 , respectively).

The recent work of Necmioglu and Özel (2015) is based on a tsunami scenarios database gridding the Eastern Mediterranean every $0.5^{\circ}$ (magnitude ranging from 6.5 to 8.5 ) and in which all sources have the regionalized fault parameters derived from the historical focal mechanisms that would generate the worst tsunami scenarios. Their results show that the tsunami amplitude expected on coastlines of Western Mediterranean (Italy, Sardinia, Sicily) would be less than $50 \mathrm{~cm}$ considering an $M \geq 8.0$ event (modeling performed on a $30^{\prime \prime}$ grid). The Eastern Corsica coastlines are located north to Sardinia.

Seven «worst-case» scenarios based on historical tsunamigenic earthquakes breaking the Hellenic subduction zone from West to East were modeled by England et al. (2015), using source parameters mainly taken from Shaw et al. (2008), with most often $20 \mathrm{~m}$ slip and $30^{\circ}$ dip. Although their results provide indications of the passage of the tsunami energy toward the Western Mediterranean basin (as far as 1-3 m of maximum wave heights modeled offshore between Tunisia and Sicily), the study is focused on the Eastern Mediterranean Sea and stops westward Sicily.

These two recent works reveal that tsunamis can impact potentially the Eastern coasts of the Western Mediterranean basin. We found it necessary to 
conduct the present study, with modeling of tsunamis generated on the Hellenic subduction zone to better assess the tsunami hazard along the French coasts and especially on the Corsica coastlines.

\section{Potential Tsunami Sources at the Hellenic Plate Boundary}

The Hellenic arc is an active deformation seismotectonic region, which extends from the SW of Greece (Cephalonia) to the South of Turkey, records a steady current seismicity (magnitude $<4.5$ ), among the most important in Europe (Fig. 1). This seismicity expresses the accommodation of the slow convergence of the Africa and Eurasia plates $(\sim 5-6 \mathrm{~mm} /$ year; McClusky et al. 2003), where rests of Mesozoic Tethysian basins are gradually consumed by the fast retreat of the subduction zone $(\sim 20-30 \mathrm{~mm} /$ year; Reilinger et al. 2006). This kinematics manifests in the activity of low-dipping thrust faults along the arc, and in normal faulting along the Aegean back-arc.

The Hellenic subduction zone is characterized at the trench by a thick accretionary prism overlying the South Greece oceanic crust over $\sim 2000 \mathrm{~km}$ length by $300 \mathrm{~km}$ width. This prism undergoes an aseismic folding deformation (Mascle and Chaumillon 1998). The deep structure of the subduction zone is rather complex and still not well known, varying along the arc, as well as the seismicity distribution. A change in normal stress along the subduction zone might be due to structural anomalies of the slab. Its detachment at
100 to $250 \mathrm{~km}$ depth (Spakman et al. 1988; Papazachos et al. 2000) beneath the Western part of Greece (Bijwaard and Spakman 1998) would spread southeastward beneath South Peloponnese and would be responsible for the compressive tectonic regime governing the Western Greek overriding plate (Meijer and Wortel 1996).

The lower limit of the Hellenic interplate seismogenic zone would be localized at $40-45 \mathrm{~km}$ depth (Shaw and Jackson 2010), in accordance with other subduction zones worldwide (Tichelaar and Ruff 1993). Focal mechanisms of interplate earthquakes reveal that the dip of the subducting plate varies between $15^{\circ}$ and $20^{\circ}$ (Taymaz et al. 1990; Meier et al. 2004; Gesret et al. 2011) and $30^{\circ}-45^{\circ}$ (Papazachos et Comninakis 1971) along the arc.

Although the occurrence of great subduction earthquakes $(M>7.5)$ is less frequent than in Japan or Chile, the Hellenic subduction zone has been affected in the past by strong events, the biggest having generated major tsunamis. Five reliable historical reports of tsunami can be closely associated with earthquakes along the Hellenic arc (England et al. 2015): 21 July AD 365 (Crete), 8 August AD 1303 (Crete; e.g., Salamon et al. 2007), 3 May AD 1481 (Rhodes), 28 February AD 1629 (Kythera), 22 January AD 1899 (Kyparissia) [see e.g., Papadopoulos (2015) for more details on these events] (Fig. 1). The last well-known earthquake sequence occurred at the end of the 19th and beginning of the 20th century, also characterized by a seismic gap on the South Peloponnese-West Crete segment. The

Table 1

Hypocenter and strike of the rupture zones associated to each of the six tsunami scenarios along the Hellenic arc (orange stars, Fig. 2)

\begin{tabular}{|c|c|c|c|c|}
\hline Source Names & Longitude $\left({ }^{\circ}\right)$ & Latitude $\left({ }^{\circ}\right)$ & Strike $\left(^{\circ}\right)$ & Source parameters from \\
\hline North Peloponnese & 21.025 & 37.1 & 320 & $\begin{array}{l}\text { Papadimitriou and Karakostas (2008) } \\
\text { Shaw et al. (2008) }\end{array}$ \\
\hline South Peloponnese & 22.125 & 36.1 & 316 & $\begin{array}{l}\text { Papadimitriou and Karakostas (2008) } \\
\text { Shaw et al. (2008) }\end{array}$ \\
\hline Western Crete & $\begin{array}{l}23.445 \\
23.505\end{array}$ & $\begin{array}{l}35.09 \\
35.125\end{array}$ & $\begin{array}{l}314 \\
315\end{array}$ & $\begin{array}{l}\text { Papadimitriou and Karakostas (2008) } \\
\text { Shaw et al. (2008) }\end{array}$ \\
\hline Eastern Crete West & 25.25 & 34.2 & 255 & $\begin{array}{l}\text { Papadimitriou and Karakostas (2008) } \\
\text { Shaw et al. (2008) }\end{array}$ \\
\hline Eastern Crete East & 26.275 & 34.55 & 242 & $\begin{array}{l}\text { Papadimitriou and Karakostas (2008) } \\
\text { Shaw et al. (2008) }\end{array}$ \\
\hline Karpathos & 27.75 & 34.75 & 236 & $\begin{array}{l}\text { Papadimitriou and Karakostas (2008) } \\
\text { Shaw et al. (2008) }\end{array}$ \\
\hline
\end{tabular}




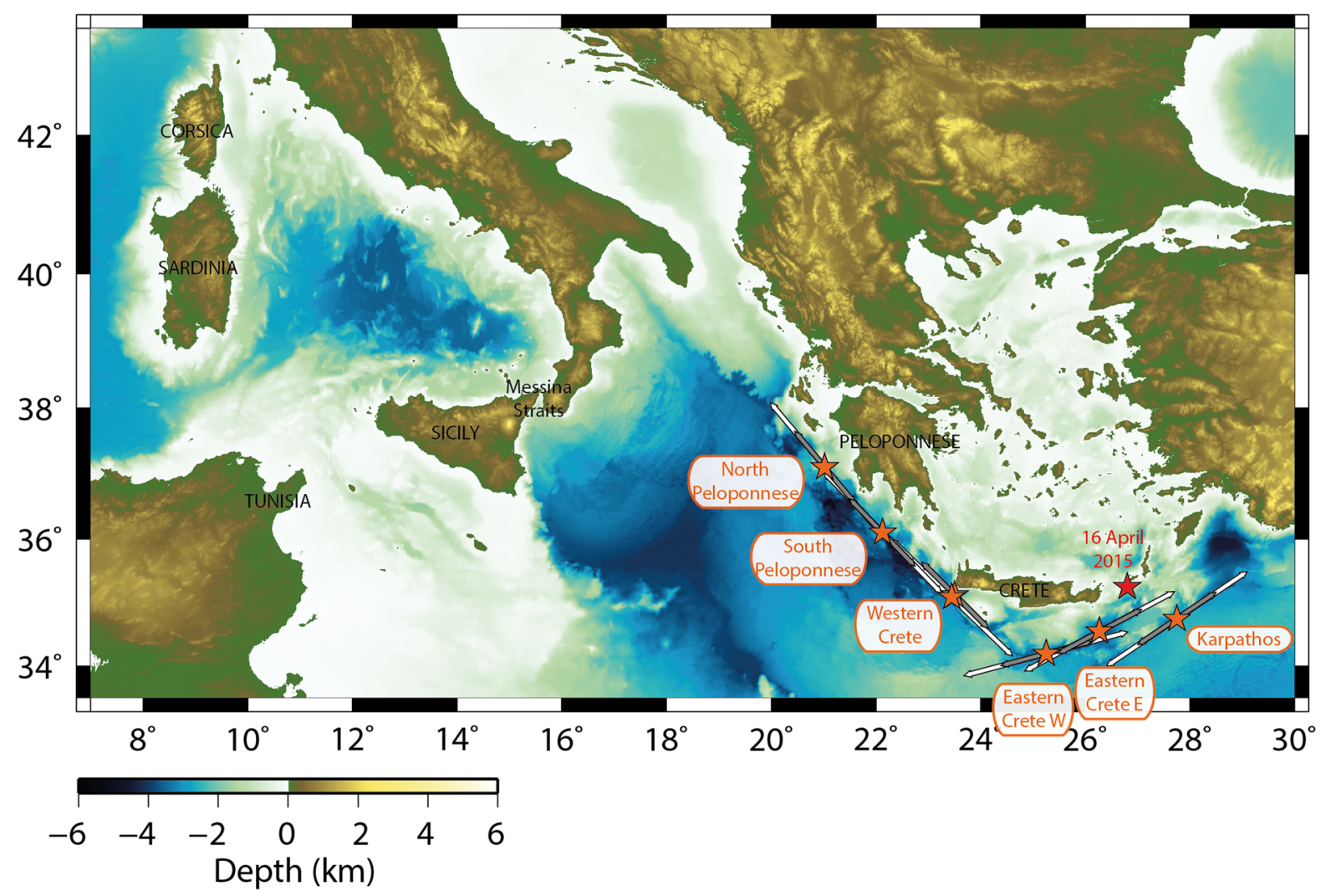

Figure 2

Location of the six tsunamigenic earthquake scenarios along the Hellenic arc (orange stars, Table 1). The white and gray bars show the sea surface extend of the two sets of source fault parameters tested (from Papadimitriou and Karakostas (2008) and from Shaw et al. (2008), respectively, Table 2) at magnitude 8.4-8.5. The red star indicates the location of the April 16, 2015 earthquake (M 6.0)

rupture of this area along a major thrust fault parallel to the trench would be the origin of the legendary great $\mathrm{AD} 365$ earthquake (estimated magnitude 8.0-8.5), which generated a huge tsunami observed as far as in the Adriatic Sea (e.g., Stiros 2010). Its return period is estimated to be $\sim 800$ years (Shaw et al. 2008).

The Hellenic arc represents one of the seismic and tsunami hazard that is the most significant in the Mediterranean basin (e.g., Shaw and Jackson 2010), but its kinematics remains uncertain, in particular as regards the degree of coupling along the interplate. The lack of subduction earthquakes to accommodate the convergence would tend to envisage some aseismic slip at the plate interface (Jackson and Mckenzie 1988; Shaw and Jackson 2010). Following this hypothesis, the Hellenic subduction zone would be weakly coupled ( $<20 \%$, Reilinger et al. 2010). This view contradicts other studies and models indicating a complete coupling (Scholz and Campos 1995; Ganas and Parsons 2009; Laigle et al. 2002).

So, the potential of $M \geq 7.5$ tsunamigenic earthquake all along the Hellenic arc exists. The question here is whether strong tsunamis could generate any impact on the French coastlines, in particular on the Eastern coasts of Corsica, which are the first French territories reached by waves. In order to characterize tsunami hazard in this area, we have modeled six scenarios based on the historical tsunamigenic sources depicted in the recent study of England et al. (2015), scanning the Hellenic subduction zone from West to East: AD 1899 (North Peloponnese), AD 1629 (South Peloponnese), AD 365 (Western Crete), AD 1303 (Eastern Crete West and East), and AD 


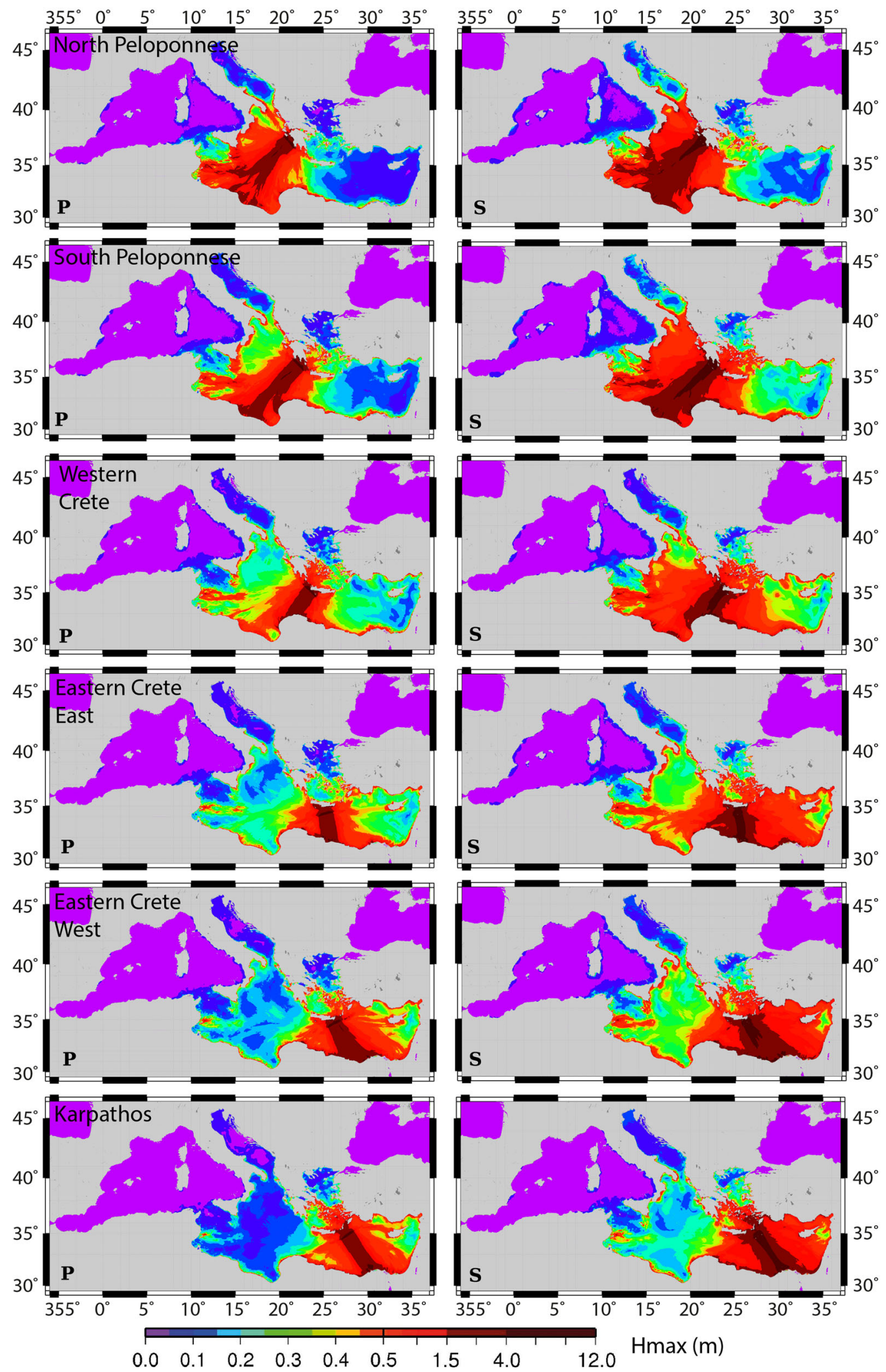


Figure 3

Maximum water heights obtained in the mother grid $\left(30^{\prime \prime}\right.$ resolution) after $12 \mathrm{~h}$ of tsunami propagation for the six scenarios at magnitude 8.4 [' $P$ ' tag, with seismic source derived from Papadimitriou and Karakostas (2008)], and 8.5 [' $S$ ' tag, with seismic source derived from Shaw et al. (2008)]. See Fig. 2 and Table 1 for reference to source location

1481 (Karpathos) (Table 1; Figs. 1, 2). The locations of these candidate sources are based on independent geological and geophysical observations of two large historical events (in Crete and Rhodes) that tend to show that such great earthquakes did not occur at the interplate subduction zone but rather on reverse faults within the overriding crust (England et al. 2015).

Following a conservative approach, we have tested two sets of source parameters (length, width and dip) established by two authors as reference for the great AD 365 tsunamigenic earthquake of estimated magnitude 8.4-8.5 (Table 2):

1. The rupture zone derived from de Papadimitriou and Karakostas (2008) is $160 \mathrm{~km}$ length by $80 \mathrm{~km}$ width. The associated slip on the fault plane for a magnitude 8.4 earthquake is set to $8.9 \mathrm{~m}$.

2. The rupture zone taken from Shaw et al. (2008) is shorter: $100 \times 88.5 \mathrm{~km}$ (length $\times$ width), with a larger fault plan slip (20 m for an 8.5 magnitude).

For each of the six scenarios, we have thus modeled the tsunami triggered by these two different seismic sources, one being quite long with a moderate slip, the other being rather stocky with a bigger slip. To obtain results both on a worst-case point of view and on the minimum impact attended, calculation on three levels of magnitude has been performed: 8.4-8.5 ("worst-case"), 8.0 and 7.8 (i.e., looking for the minimum magnitude required for the tsunami to be observed in the Western Mediterranean basin;
Necmioglu and Özel 2015). Associated source parameters are reported in Table 2.

\section{Tsunami Calculation Method}

The numerical method involves modeling of the initiation, propagation, and runup of the tsunami waves. The computation of the initial seafloor perturbation responsible for the tsunami triggering uses coseismic static ground displacement for a uniform dislocation in an elastic half-space (Okada 1985), assumed to be instantaneously and fully transmitted to the water column.

Under the nondispersive shallow water assumption, propagation in the deep ocean is solved through a finite difference scheme taking into account the nonlinear terms of the depth-averaged hydrodynamical equations describing the conservation of mass (1) and momentum (2):

$$
\begin{aligned}
& \frac{\partial(\eta+h)}{\partial t}+\nabla \cdot[\boldsymbol{v}(\eta+h)]=0 \\
& \frac{\partial \boldsymbol{v}}{\partial t}+(\boldsymbol{v} \cdot \nabla) \boldsymbol{v}=-g \nabla \eta+\mathbf{f},
\end{aligned}
$$

where $h$ is the water depth, $\eta$ the water elevation above mean sea level, $v$ the depth-averaged horizontal velocity vector, $g$ the scalar acceleration of gravity, and $\boldsymbol{f}$ the combination of bottom friction and Coriolis forces, both of them being in general first order in $v$ and being neglected. These equations are solved using a Crank-Nicolson method centered in time, with an upwind scheme in space (see Hébert et al. (2001) for more details on the numerical method).

The main drawback of the finite difference method is the constant spatial increment over the

Table 2

\begin{tabular}{|c|c|c|c|c|c|c|}
\hline \multirow{2}{*}{$\begin{array}{l}\text { Source parameters } \\
\text { Length }(\mathrm{km})\end{array}$} & \multicolumn{3}{|c|}{ From Papadimitriou and Karakostas (2008) } & \multicolumn{3}{|c|}{ From Shaw et al. (2008) } \\
\hline & 160 & & & 100 & & \\
\hline Width $(\mathrm{km})$ & 80 & & & 88.5 & & \\
\hline $\operatorname{Dip}\left({ }^{\circ}\right)$ & 35 & & & 30 & & \\
\hline Depth $(\mathrm{km})$ & 23.5 & & & 22.6 & & \\
\hline Magnitude & 8.4 & 8.0 & 7.8 & 8.5 & 8.0 & 7.8 \\
\hline Slip (m) & 8.9 & 2.4 & 1.2 & 20 & 3.5 & 1.8 \\
\hline
\end{tabular}

Rupture zone parameters for the two seismic sources tested for each scenario 

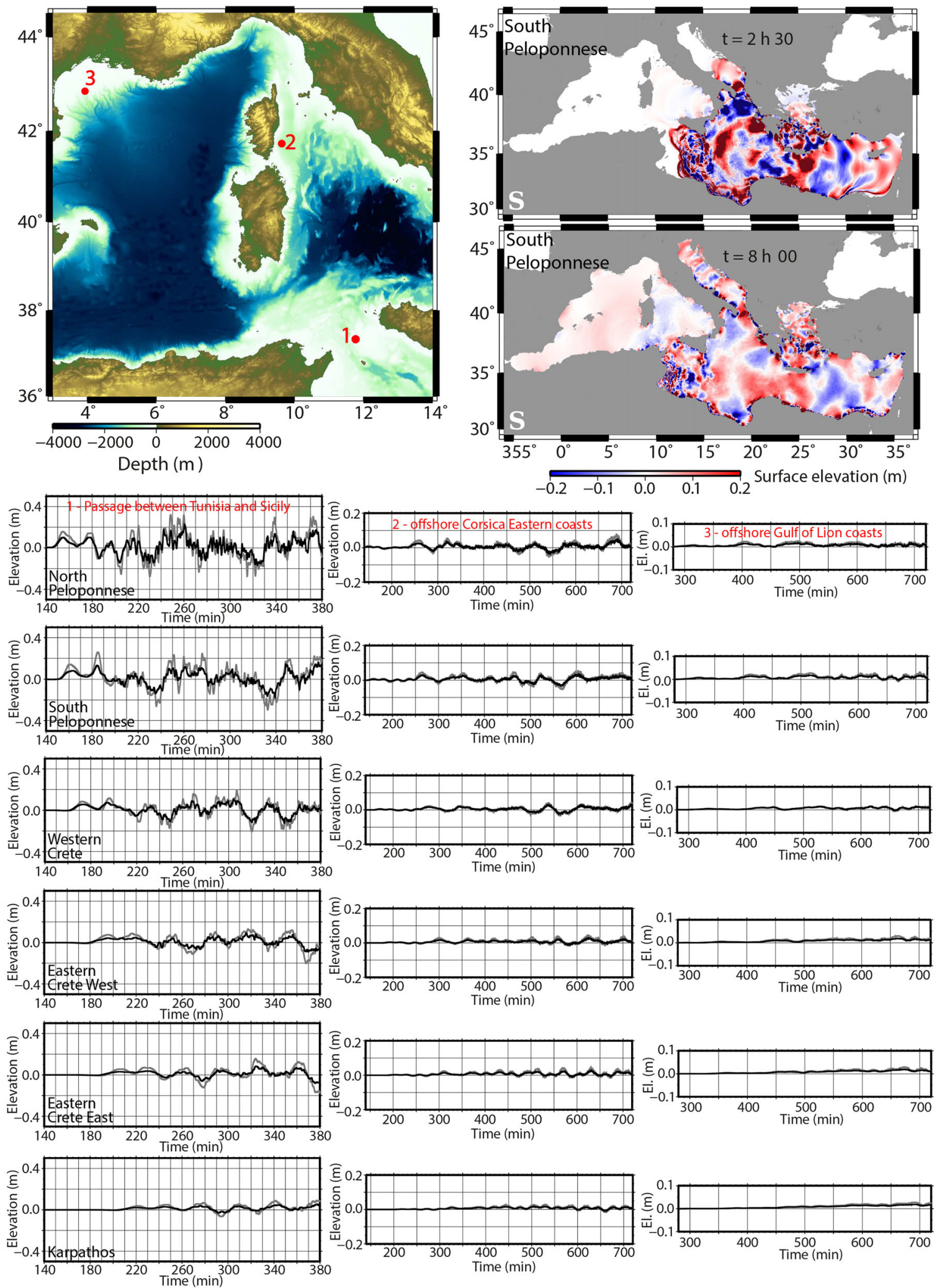
Figure 4

Synthetic tide gage records for each scenario at magnitude 8.4-8.5 at locations of interest in the Western Mediterranean basin: (left) passage between Tunisia and Sicily_buoy depth $104 \mathrm{~m}$, (middle) offshore the Eastern coast of Corsica-buoy depth $802 \mathrm{~m}$, (right) offshore Gulf of Lion coasts-buoy depth $333 \mathrm{~m}$. (gray curve) results obtained using seismic source parameters from Papadimitriou and Karakostas (2008). (Black curve) results obtained using seismic source parameters from Shaw et al. (2008). Map at the top left shows the location of the synthetic gages. At the top right are shown the sea surface states at basin scale $2 \mathrm{~h} 30$ (top) and $8 \mathrm{~h}$ (bottom) after the earthquake in the case of the South Peloponnese scenario at magnitude 8.5 (with seismic source derived from Shaw et al. 2008)

whole computation grid. To deal with amplification effects of the tsunami waves, detailed bathymetric grids are used for a more accurate modeling of the coastline response in bays and harbors. To this end, we calculated wave propagation on three successive levels of nested grids of increasing resolution close to the coastlines, built using available bathymetric data. The two lower resolution grids use the GEBCO World Bathymetry (resolution 30" and $400 \mathrm{~m} \mathrm{IOC,}$ IHO and BODC (2003), and geographical extension $6^{\circ} \mathrm{W} / 37^{\circ} \mathrm{E} / 29.5^{\circ} \mathrm{N} / 46.3^{\circ} \mathrm{N}$ and $7.5^{\circ} \mathrm{E} / 10.6^{\circ} \mathrm{E} / 40.5^{\circ} \mathrm{N} /$ $43.7^{\circ} \mathrm{N}$, respectively). The higher resolution grid zooms on Corsica (100 m cell-size grid, geographical extension: $7.7^{\circ} \mathrm{E} / 10.4^{\circ} \mathrm{E} / 40.7^{\circ} \mathrm{N} / 43.3^{\circ} \mathrm{N}$ ). This finer grid comes from the SHOM open database (HOMONIM project, doi:10.17183/ MNT_MED100M_CORSE_HOMONIM_WGS84).

Unfortunately, this level of resolution is not high enough to model the shoaling and resonance effects at harbor and bay scale. Thus, the calculation is performed without taking into account the inundation of the coastal areas, whereas the method can handle it. Thus, the results will provide a more regional assessment at the coastal level, further refinements being required for specific locations.

Open free boundary conditions are prescribed to the boundaries of the grid covering the Mediterranean basin, and wave heights along the boundaries of a fine grid are spatially interpolated at each time step from the value computed in the coarse grid containing the fine grid. This tsunami modeling code has been used worldwide and has proven its efficiency, especially in the Pacific through the simulation of waves triggered by historical and great earthquakes of the last decades where abundant data are available to validate the simulations (e.g., Hébert et al. 2007, 2009; Reymond et al. 2012). The code is also implemented on multiprocessor computers within the French tsunami warning center (CENALT), and used as an "on-thefly" operational tsunami modeling tool (Schindelé et al. 2015).

In the following, the tsunami modeling results are presented after $12 \mathrm{~h}$ of real-time propagation.

\section{Impact of Tsunami on Corsica}

\subsection{Worst-Case Results}

The results of worst-case scenario are analyzed at basin scale as well as at Corsica scale. At basin scale (i.e., in the $30^{\prime \prime}$ mother grid), the calculation performed for a 8.4-8.5 magnitude earthquake shows that a tsunami impact is modeled in Western Mediterranean whatever the area of the Hellenic subduction zone ruptured (Fig. 3). The easternmost scenario (Karpathos) generates the lower impact along the French coasts, with maximum waves amplitudes entering the passage between Tunisia and Sicily up to 3 times smaller than the ones generated by the western scenarios (Fig. 4, right). Sources in South Crete and Peloponnese are able to trigger a tsunami reaching as far as the Gulf of Lion and the Provence region. However, a synthetic gage located in the Gulf of Lion indicates that offshore maximum wave amplitudes do not exceed $4 \mathrm{~cm}$ in any case (Fig. 4, left). For each scenario, the tsunami energy due to the 8.5 magnitude source with a strong slip [20 m, rupture zone parameters from Shaw et al. (2008), Table 2] is systematically a little higher, as the effects toward the French coastlines, reaching up to $60 \mathrm{~cm}$ peak-to-trough in deep ocean between Tunisia and Sicily in the case of the Peloponnese scenarios (Fig. 4, left). Offshore the eastern coast of Corsica, the maximum wave amplitudes modeled are about $\sim 8 \mathrm{~cm}$ peak-to-trough for the same scenarios (Fig. 4, middle). Evolution of surface elevation through time reveals that the tsunami is able to cross both the Tunisia-Sicily passage and the Messina Straight (after $\sim 2 \mathrm{~h} 30$ of real-time propagation in the case of scenario 'South Peloponnese.' Fig. 4, top right). 

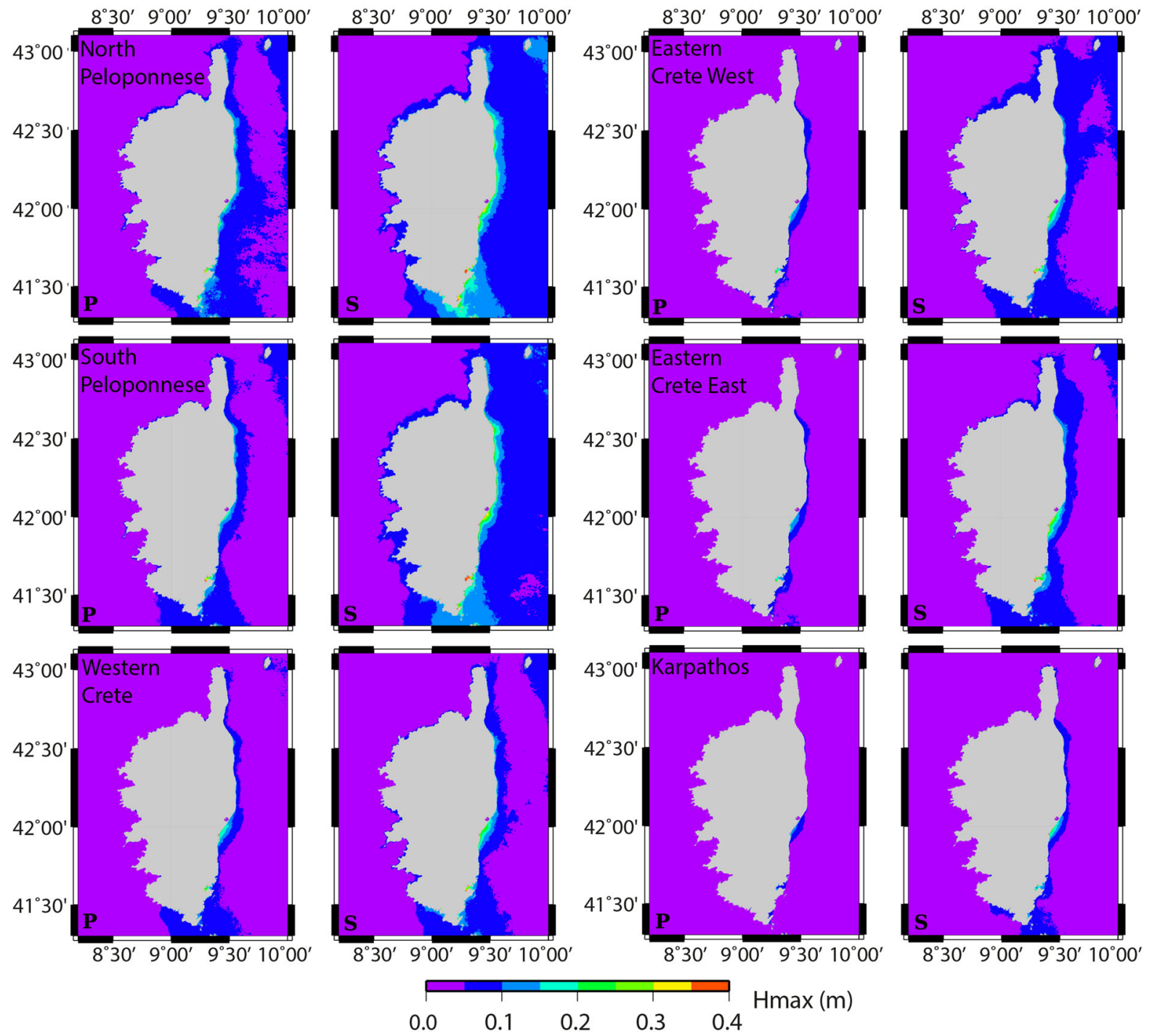

Figure 5

Maximum water heights obtained in the Corsica daughter grid (100 m resolution) after $12 \mathrm{~h}$ of tsunami propagation for the six scenarios at magnitude 8.4 [' $P$ ' tag, with seismic source derived from Papadimitriou and Karakostas (2008)], and 8.5 [' $S$ ' tag, with seismic source derived from Shaw et al. (2008)]. See Fig. 2 and Table 1 for reference to source location

At the Corsica scale (i.e., in the 100-m resolution daughter grid), the worst-case scenarios' results show that the tsunami impact is mainly located along the Eastern and Southern coasts of the island (Fig. 5). The westernmost scenarios (Peloponnese) provide the larger impact, with clues of amplification in particular bays and beaches, such as in the Porto Vecchio and Solenzara areas (Fig. 6). The tsunami modeling obtained with the Shaw et al. (2008) rupture zone parameters provides higher wave heights, with up to
40-50 cm locally along the Eastern coasts of Corsica, and for several scenarios, the tsunami can also reach the Western coast, with lower wave heights (Fig. 5). Synthetic gages located offshore these areas of interest indicate that maximum wave amplitudes modeled do not exceed $10 \mathrm{~cm}$ peak-to-trough close to Ajaccio, and $20 \mathrm{~cm}$ near Bonifacio and Bastia (Fig. 6). The tsunami waves crossing the Messina Straits are the first to reach Eastern Corsica, then the ones coming from the Tunisia-Sicily passage come 

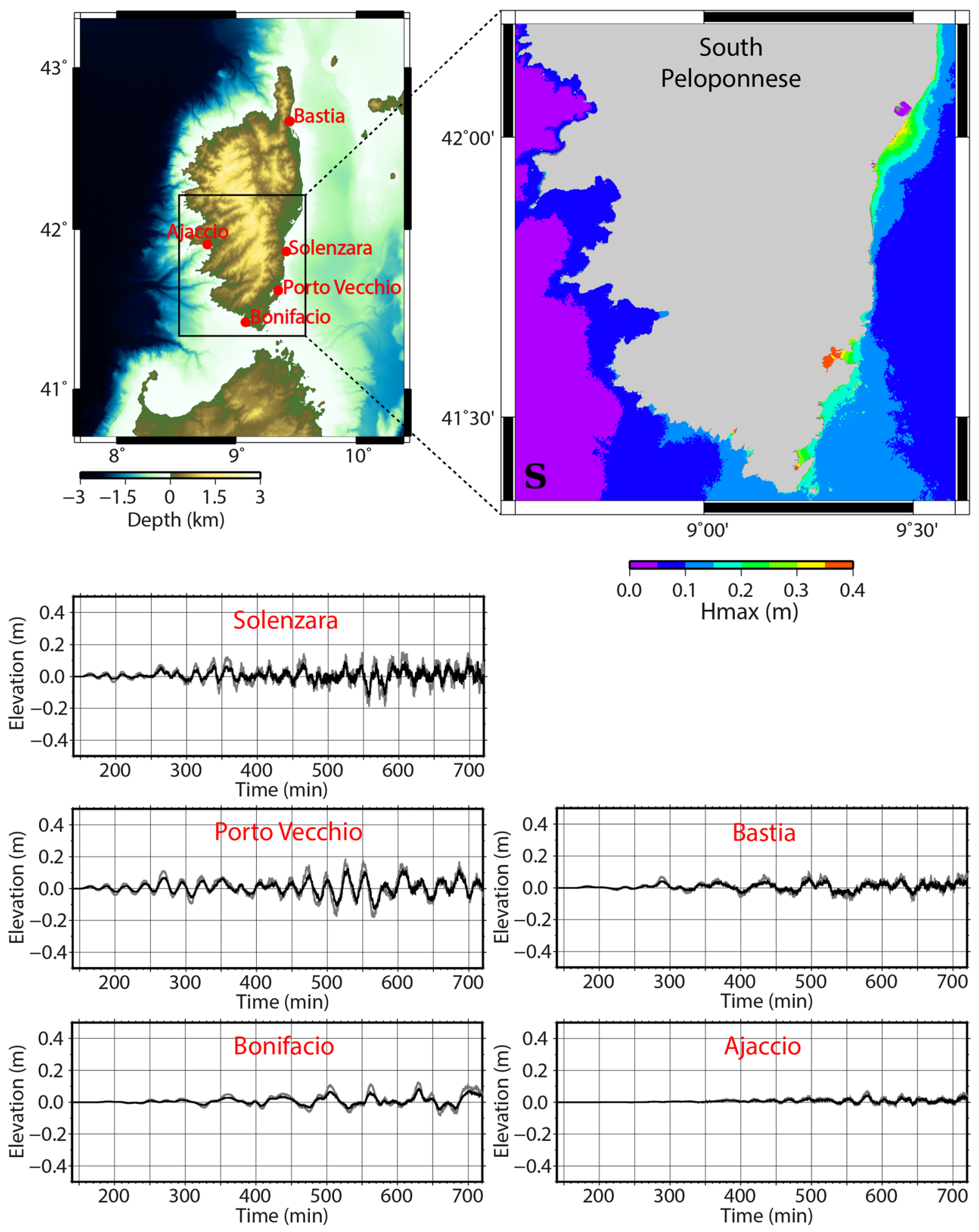
Figure 6

Synthetic tide gage records for the South Peloponnese 'worst-case' scenario at magnitude 8.4-8.5 at locations of interest along the Corsica coastlines. (Gray curve) Results obtained using seismic source parameters from Papadimitriou and Karakostas (2008). (black curve) results obtained using seismic source parameters from Shaw et al. (2008). Map at the top left shows the location of the synthetic gages. Map at the top right is a detailed view of the maximum water heights obtained in the Corsica daughter grid (100-m resolution) after $12 \mathrm{~h}$ of tsunami propagation for the South Peloponnese scenario at magnitude 8.5 (with seismic source derived from Shaw et al. 2008). Buoys depth: $19 \mathrm{~m}$ (Ajaccio), $30 \mathrm{~m}$ (Bastia), $30 \mathrm{~m}$ (Bonifacio), $23 \mathrm{~m}$ (Porto Vecchio), $96 \mathrm{~m}$ (Solenzara)

strengthening the signal amplitude $\sim 7 \mathrm{~h} 30$ after the earthquake. This is clearly observable on the synthetic gage located at the entrance of the Porto Vecchio bay, where first arrivals of up to $\sim 15 \mathrm{~cm}$ amplitude appear from $2 \mathrm{~h} 30$ after the earthquake, then the wave train amplitude is reinforced to up to $\sim 40 \mathrm{~cm}$ between $7 \mathrm{~h} 30$ and $10 \mathrm{~h}$ (450-600 min, Fig. 6).

\subsection{Minimum Magnitude for a Tsunamigenic Earthquake to Impact Corsica}

One of the mandate of a national tsunami warning center is to assess the expected tsunami impact on the national coastlines and to establish the criteria of the specific national alert or threat level decision methods.

In order to evaluate the minimum magnitude required for a tsunami to cross from Eastern to Western Mediterranean, and to estimate a potential impact along the French coasts, modeling of worstcase scenarios at magnitude $8.4-8.5$ was performed lowering the magnitude down to 8.0 and 7.8 (Table 2; Figs. 7, 8). The calculations were run for the six sources (North Peloponnese, South Peloponnese, Western Crete and Eastern Crete (West and East segments), Karpathos). We represent here the maximum of the maximum wave heights modeled for these six scenarios, considering rupture zone parameters modified from Papadimitriou and Karakostas (2008) and Shaw et al. (2008) at magnitude 8.0 and 7.8 (Figs. 7, 8).

When lowering the magnitude, the effect of the tsunami in Western Mediterranean is attenuated logically, with offshore maximum water heights that rarely exceed $5 \mathrm{~cm}$ along the French coasts at magnitude 8.0. Moreover, a small portion of the Eastern Corsica coastlines is only affected by the tsunami, but it is still limited (Fig. 7). The higher amplification is once again modeled in the Porto Vecchio and Solenzara areas $(10 \mathrm{~cm}$ in the bay of Porto Vecchio at maximum). The results obtained with both rupture zone parameters [i.e., modified from Papadimitriou and Karakostas (2008) and Shaw et al. (2008)] show similar maximum wave heights distribution and amplitude. A test was also performed at magnitude 8.0 increasing the slip of the sources to $5 \mathrm{~m}$ (taking into account a $90 \times 70 \mathrm{~km}$ rupture zone area). The conclusion in that case is that the associated modeling does not provide higher water heights along Corsica.

At magnitude 7.8 , the tsunami generated is not energetic enough to cross from Eastern to Western Mediterranean and no effect is obtained along the French coasts (modeled maximum wave heights of less than $5 \mathrm{~cm}$, Fig. 8).

\section{Discussion and Conclusion}

The modeling of six different sources' scenarios along the Hellenic subduction zone, with different levels of magnitude, based on historical tsunamigenic earthquake locations (England et al. 2015), shows that a tsunami hazard exists along the French coasts for earthquakes of magnitude $\geq 8.0$ generated along the Hellenic arc. The largest impact is obtained for sources rupturing the South (Crete area) and Western (Peloponnese) parts of the subduction zone.

Along the Corsica coasts, the tsunami effect varies, depending on the magnitude and configuration of the source modeled. Maximum wave heights of 5 to $40-50 \mathrm{~cm}$ could be expected close to the shore. The calculation being done on a $100-\mathrm{m}$ resolution grid, specific bathymetric features or amplifying coastal geometries (like in the Porto Vecchio bay) are not taken well into account in the modeling. Using the Green's law empirical amplification relation (Green 1837) expressing conservation of wave energy flux: $\eta 2=\eta 1(h 1 / h 2)^{1 / 4}$, to prolong the gridded wave field $\eta$ into the harbor at depth $h 2$ with respect to a nearby deep-water grid point at depth $h 1$, coastal water 

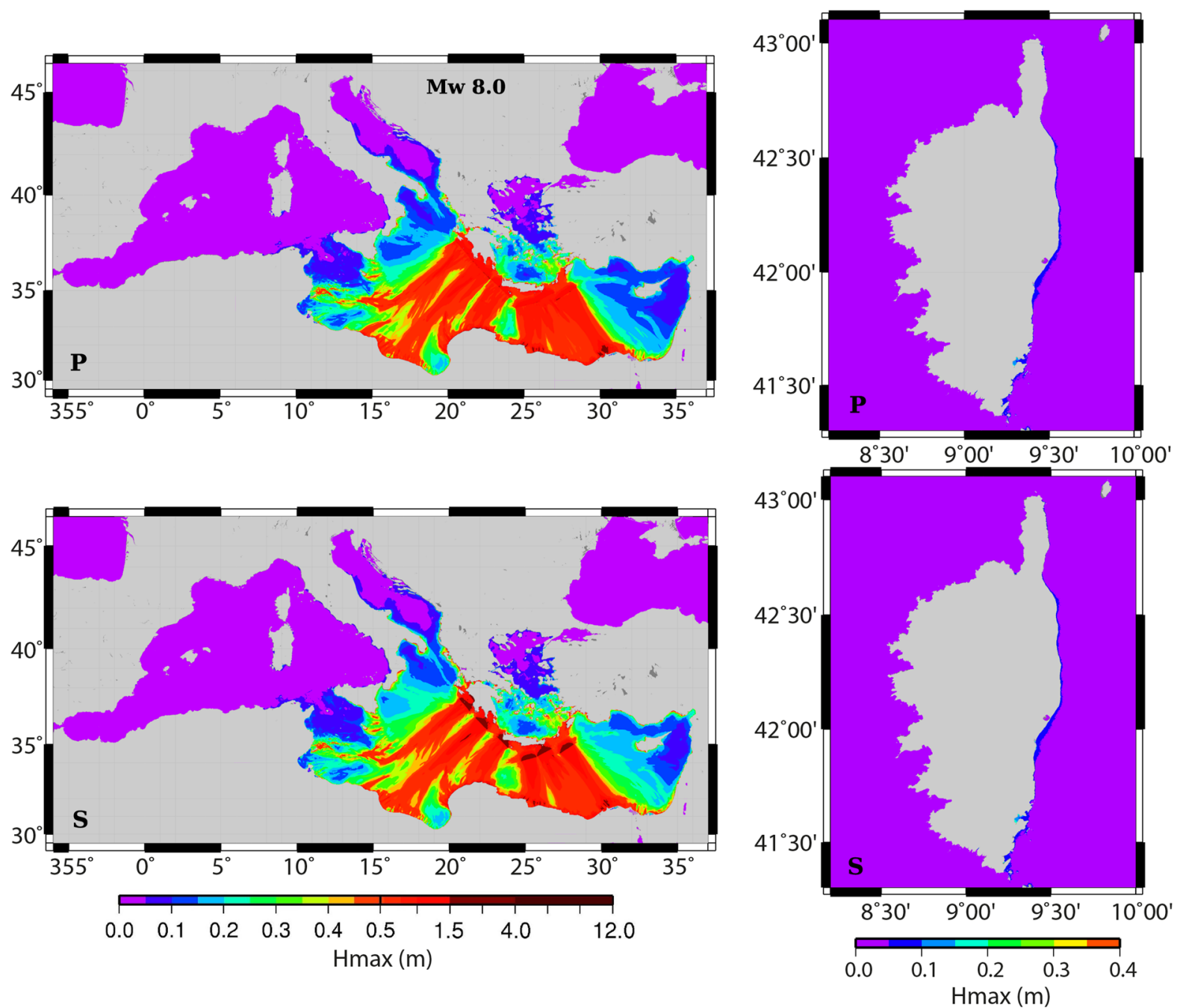

Figure 7

Maximum of the maximum water heights obtained in the mother grid ( $30^{\prime \prime}$ resolution, left) and in the Corsica daughter grid (100 m resolution, right) after $12 \mathrm{~h}$ of tsunami propagation from the six scenarios, at magnitude 8.0 (' $P$ ' and ' $S$ ' tag, with seismic source derived from Papadimitriou and Karakostas (2008) and from Shaw et al. (2008), respectively). See Table 2 for reference to source parameters

heights can be approximated in first order from $15 \mathrm{~cm}$ to $1.5 \mathrm{~m}$. This constitutes a drastic approximation, as the complex response of a particular harbor does not follow Green's law exactly: tsunami amplification or attenuation due to specific harbors or bays configuration (e.g., breakwaters) is not taken into account there. The more accurate way to account for these amplification or attenuation phenomena would be to perform a numerical tsunami propagation and inundation modeling by using several nested bathymetric grids characterized by a coarse resolution over deep water regions and an increasingly fine resolution close to the shores. The results of this kind of modeling generally provide coastal wave heights $2-5$ times larger than what is modeled on a coarse grid alone. That means between the water heights obtained in this study on the $100-\mathrm{m}$ resolution grid and maximum wave heights to expect at harbor and bay scale (or what would be modeled using highresolution nested grids), a multiplying factor of 2 to 4-5 could be observed (e.g., Tanioka et al. 2004). For the worst-case scenarios, that means tsunami waves 

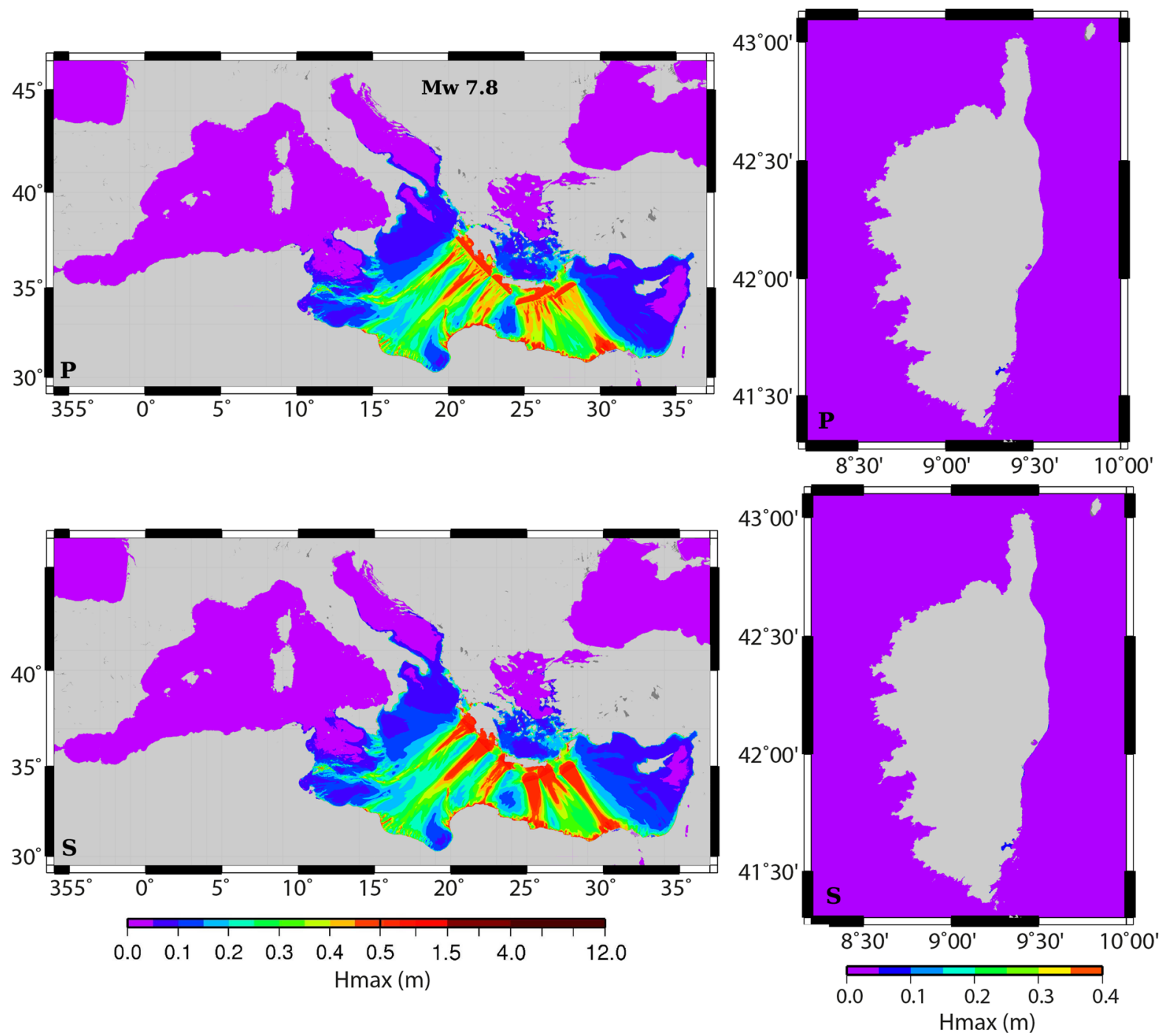

Figure 8

Maximum of the maximum water heights obtained in the mother grid $\left(30^{\prime \prime}\right.$ resolution, left $)$ and in the Corsica daughter grid (100 $\mathrm{m}$ resolution, right) after $12 \mathrm{~h}$ of tsunami propagation from the six scenarios, at magnitude 7.8 [' $\mathrm{P}$ ' and ' $\mathrm{S}$ ' tag, with seismic source derived from

Papadimitriou and Karakostas (2008) and from Shaw et al. (2008), respectively]. See Table 2 for reference to source parameters

of up to 2-2.5 m amplitude could impact the Eastern Corsica coastlines, especially in the Porto Vecchio and Solenzara areas. Tsunami modeling with higher resolution bathymetry-topography grids would allow more accurate simulations at harbor and bay scale, and would help to assess the runup expected in the key sectors of these regions.

Rupture zone parameters used for each scenario reveal their influence on the variation in the tsunami energy triggered and its directivity. For a similar range of magnitude (i.e., 8.0-8.5), using a longer and smaller source with a lower dip and slip will decrease the energy potential of the tsunami, leading to the absence of tsunami effect in the Western Mediterranean basin (e.g., Tinti et al. 2005). On the other hand, using shorter rupture zones with higher slips, which is more consistent with the geological and geophysical structure of the Hellenic subduction zone (England et al. 2015), provides synthetic tsunami able to generate effects along the French coasts. And for a 
given magnitude, the highest the slip is, the largest the wave heights modeled are, as shown by the difference obtained between using source parameters from Papadimitriou and Karakostas (2008) and Shaw et al. (2008).

It is, however, important to keep in mind that the large-scale tsunami scenarios modeled are built from historical and geological data, which are very sparse, and that rupture zone parameters (fault dimension, slip) used cannot be linked to the present-day rates of seismicity. They must be considered as extreme events associated to a long-term recurrence interval. The current strain estimated from GPS that could be released in earthquakes along the faults on which our scenarios are based could differ by a factor 10 or more (Shaw et al. 2008; Vernant et al. 2014; Ganas and Parsons 2009). This is observed frequently for areas characterized by a high recurrence period (a priori more than 1000-2000 years), as for example the North zone of Sumatra before 2004. Such uncertainties must be taken into account in this conservative hazard assessment approach and precaution must be taken in the results interpretation.

The results of this study contribute to establish the specific criteria of the alert chain for the French coastlines. This shows the need for carrying out such kind of research, as well as the importance of performing numerical tsunami modeling, especially in areas characterized by a lack of historical data and a low occurrence of big events. Two thresholds are considered, corresponding to the decision matrix used in the warning procedure and described in Schindelé et al. (2015). For earthquakes of magnitude greater than 7.8/8.3 occurring along the Hellenic arc, an advisory/watch level message, with expected inundation along sections of the coastlines, would be transmitted by CENALT to the French civil protection authorities. For events of magnitude between 6.5 and 7.8, an information message would be sent by the CENALT. The advisory level corresponds to a wave height from 20 to $50 \mathrm{~cm}$, watch level greater than $50 \mathrm{~cm}$, and information level less than $20 \mathrm{~cm}$. In the case of the April 16, 2015 Hellenic event, no message would have been sent by the CENALT, in accordance with the procedures defined between the civil protection authorities and the CENALT, the latter being the unique reference center for the French authorities.
The goal of the values of magnitude adopted for the Hellenic arc is primarily (1) to remain conservative and (2) to keep simple criteria in the operational scope, as requested by the civil protection authorities.

These values of magnitude are much larger than the typical threshold values defined for the Mediterranean Sea: 6.5 for a basin-wide advisory level and 7.0 for a basin-wide watch level. This will increase the efficiency of the CENALT tsunami warning system and procedures, in reducing the number of unnecessary alert and evacuations.

\section{Acknowledgments}

We thank the two anonymous reviewers for their valuable review and suggestions that improve this manuscript. We thank the Service Hydrographique et Océanographique de la Marine (SHOM) for the bathymetric data they kindly provided in the Corsica area (http://www.shom.fr/ les-services-en-ligne/portail-datashomfr).

Open Access This article is distributed under the terms of the Creative Commons Attribution 4.0 International License (http:// creativecommons.org/licenses/by/4.0/), which permits unrestricted use, distribution, and reproduction in any medium, provided you give appropriate credit to the original author(s) and the source, provide a link to the Creative Commons license, and indicate if changes were made.

\section{REFERENCES}

Bijwaard, H., Spakman, W., \& Engdahl, E. R. (1998). Closing the gap between regional and global travel time tomography. Journal of Geophysical Research: Solid Earth, 103(12), 30055-30078.

Dziewonski, A. M., Chou, T.-A., \& Woodhouse, J. H. (1981). Determination of earthquake source parameters from waveform data for studies of global and regional seismicity. Journal of Geophysical Research: Solid Earth, 86, 2825-2852. doi:10.1029/ JB086iB04p02825.

Ekström, G., Nettles, M., \& Dziewonski, A. M. (2012). The global CMT project 2004-2010: centroid-moment tensors for 13,017 earthquakes. Physics of the Earth and Planetary Interiors, 200-201, 1-9. doi:10.1016/j.pepi.2012.04.002.

Ganas, A., \& Parsons, T. (2009). Three dimensional model of Hellenic Arc deformation and origin of the Cretan uplift. Journal of Geophysical Research: Solid Earth (1978-2012), 114(B6).

Gesret, A., Laigle, M., Diaz, J., Sachpazi, M., Charalampakis, M., \& Hirn, A. (2011). Slab top dips resolved by teleseismic converted waves in the Hellenic subduction zone. Geophysical Research Letters, 38(20). 
Green, G. (1837). On the motion of waves in a variable canal of small depth and width. Transactions of the Cambridge Philosophical Society, 6, 457-462.

Hébert, H., Heinrich, P., Schindelé, F., \& Piatanesi, A. (2001). Farfield simulation of tsunami propagation in the Pacific Ocean: impact on the Marquesas Islands (French Polynesia). Journal of Geophysical Research: Oceans, 106(C5), 9161-9177.

Hébert, H., Reymond, D., Krien, Y., Vergoz, J., Schindelé, F., Roger, J., \& Loevenbruck, A. (2009). The 15 August 2007 Peru earthquake and tsunami: influence of the source characteristics on the tsunami heights. Pure and Applied Geophysics, 166(1-2), 211-232.

Hébert, H., Sladen, A., \& Schindelé, F. (2007). Numerical modeling of the great 2004 Indian Ocean tsunami: focus on the Mascarene Islands. Bulletin of the Seismological Society of America, 97(1A), S208-S222.

England, P.H., Howell, A., Jaskson, J. \& Synolakis, C. (2015). Palaeotsunamis and tsunami hazards in the Eastern Mediterranean. Phil. Trans. R. Soc. A273:20140374. doi:10.1098/rsta. 2014.0374 .

IOC, IHO and BODC. (2003). Centenary Edition of the GEBCO Digital Atlas, published on CD-ROM on behalf of the Intergovernmental Oceanographic Commission and the International Hydrographic Organization as part of the General Bathymetric Chart of the Oceans, British Oceanographic Data Centre, Liverpool, UK.

Jackson, J., \& McKenzie, D. (1988). The relationship between plate motions and seismic moment tensors, and the rates of active deformation in the Mediterranean and Middle East. Geophysical Journal International, 93(1), 45-73.

Laigle, M., Hirn, A., Sachpazi, M., \& Clément, C. (2002). Seismic coupling and structure of the Hellenic subduction zone in the Ionian Islands region. Earth and Planetary Science Letters, 200(3), 243-253.

Mascle, J., \& Chaumillon, E. (1998). An overview of Mediterranean Ridge collisional accretionary complex as deduced from multichannel seismic data. Geo-Marine Letters, 18(2), 81-89.

McClusky, S., Reilinger, R., Mahmoud, S., Sari, D. B., \& Tealeb, A. (2003). GPS constraints on Africa (Nubia) and Arabia plate motions. Geophysical Journal International, 155(1), 126-138.

Meier, T., Rische, M., Endrun, B., Vafidis, A., \& Harjes, H. P. (2004). Seismicity of the Hellenic subduction zone in the area of western and central Crete observed by temporary local seismic networks. Tectonophysics, 383(3), 149-169.

Meijer, P. T., \& Wortel, M. J. R. (1996). Temporal variation in the stress field of the Aegean region. Geophysical Research Letters, 23(5), 439-442.

Necmioglu, O., \& Özel, N. M. (2015). Earthquake ScenarioBased Tsunami Wave Heights in the Eastern Mediterranean and Connected Seas. Pure and Applied Geophysics, 172(12), 3617-3638.

Okada, Y. (1985). Surface deformation due to shear and tensile faults in a half-space. Bull. Seism. Soc. Am, 75, 1135-1154.

Papadimitriou, E. E., \& Karakostas, V. G. (2008). Rupture model of the great AD 365 Crete earthquake in the southwestern part of the Hellenic Arc. Acta Geophysica, 56(2), 293-312.

Papadopoulos, G. A. (2003). Tsunami hazard in the Eastern Mediterranean: strong earthquakes and tsunamis in the Corinth Gulf, Central Greece. Natural Hazards, 29(3), 437-464.

Papadopoulos, G. (2015). Tsunamis in the European-Mediterranean region: from historical record to risk mitigation. Elsevier.
Papadopoulos, G. A., Daskalaki, E., Fokaefs, A., \& Giraleas, N. (2007). Tsunami hazards in the Eastern Mediterranean: strong earthquakes and tsunamis in the East Hellenic Arc and Trench system. Natural Hazards and Earth System Science, 7(1), 57-64.

Papazachos, B. C., \& Comninakis, P. E. (1971). Geophysical and tectonic features of the Aegean Arc. Geophysical Journal International, 76, 8517-8533.

Papazachos, B. C., Karakostas, V. G., Papazachos, C. B., \& Scordilis, E. M. (2000). The geometry of the Wadati-Benioff zone and lithospheric kinematics in the Hellenic arc. Tectonophysics, 319(4), 275-300.

Reilinger, R., McClusky, S., Paradissis, D., Ergintav, S., \& Vernant, P. (2010). Geodetic constraints on the tectonic evolution of the Aegean region and strain accumulation along the Hellenic subduction zone. Tectonophysics, 488(1), 22-30.

Reilinger, R., McClusky, S., Vernant, P., Lawrence, S., Ergintav, S., Cakmak, R., \& Karam, G. (2006). GPS constraints on continental deformation in the Africa-Arabia-Eurasia continental collision zone and implications for the dynamics of plate interactions. Journal of Geophysical Research: Solid Earth (1978-2012), 111(B5).

Reymond, D., Okal, E. A., Hébert, H., \& Bourdet, M. (2012). Rapid forecast of tsunami wave heights from a database of precomputed simulations, and application during the 2011 Tohoku tsunami in French Polynesia. Geophysical Research Letters, 39, L11603. doi:10.1029/2012GL051640.

Salamon, A., Rockwell, T., Ward, S. N., Guidoboni, E., \& Comastri, A. (2007). Tsunami hazard evaluation of the eastern Mediterranean: historical analysis and selected modeling. Bulletin of the Seismological Society of America, 97(3), 705-724.

Schindelé, F., Gailler, A., Hébert, H., Loevenbruck, A., Gutierrez, E., Monnier, A., et al. (2015). Implementation and challenges of the Tsunami Warning System in the Western Mediterranean. Pure and Applied Geophysics, 172(3-4), 821-833.

Scholz, C. H., \& Campos, J. (1995). On the mechanism of seismic decoupling and back arc spreading at subduction zones. Journal of Geophysical Research: Solid Earth (1978-2012), 100(B11), 22103-22115.

Shaw, B., Ambraseys, N. N., England, P. C., Floyd, M. A., Gorman, G. J., Higham, T. F. G., et al. (2008). Eastern Mediterranean tectonics and tsunami hazard inferred from the AD 365 earthquake. Nature Geoscience, 1(4), 268-276.

Shaw, B., \& Jackson, J. (2010). Earthquake mechanisms and active tectonics of the Hellenic subduction zone. Geophysical Journal International, 181(2), 966-984.

Spakman, W., Wortel, M. J. R., \& Vlaar, N. J. (1988). The Hellenic subduction zone: a tomographic image and its geodynamic implications. Geophysical Research Letters, 15(1), 60-63.

Stiros, S. C. (2010). The 8.5+ magnitude, AD365 earthquake in Crete: coastal uplift, topography changes, archaeological and historical signature. Quaternary International, 216(1), 54-63.

Tanioka, Y., Nishimura, Y., Hirakawa, K., Imamura, F., Abe, I., Abe, Y., et al. (2004). Tsunami run-up heights of the 2003 Tokachi-oki earthquake. Earth, Planets and Space, 56(3), 359-365.

Taymaz, T., Jackson, J., \& Westaway, R. (1990). Earthquake mechanisms in the Hellenic Trench near Crete. Geophysical Journal International, 102(3), 695-731.

Tichelaar, B. W., \& Ruff, L. J. (1993). Depth of seismic coupling along subduction zones. Journal of Geophysical Research: Solid Earth (1978-2012), 98(B2), 2017-2037. 
Tinti, S., Armigliato, A., Pagnoni, G., \& Zaniboni, F. (2005). Scenarios of giant tsunamis of tectonic origin in the Mediterranean. ISET Journal of Earthquake Technology, 42(4), 171-188.
Vernant, P., Reilinger, R., \& McClusky, S. (2014). Geodetic evidence for low coupling on the Hellenic subduction plate interface. Earth and Planetary Science Letters, 385, 122-129.

(Received April 28, 2016, revised July 22, 2016, accepted July 25, 2016, Published online August 11, 2016) 